\title{
Blood Supply of the Trigeminal Ganglion of the Dog
}

\author{
By \\ Hitoshi OKUDA \\ Department of Anatomy, Osaka Dental University, \\ Kyobashi, Higashi-ku, Osaka 540, Japan \\ (Director: Prof. Y. Ohta) \\ -Received for Publication, February 5, 1979-
}

Key Words: Trigeminal ganglion, Comparative anatomy, Blood supply, Plastic injection, Dog.

\begin{abstract}
Summary. The author has investigated the arterial distribution of the trigeminal ganglion in the dog by means of the acryl plastic injection method, and additionally the basic structure and topographical relations of the ganglion.

1. Most of the ganglion was located in the impressio trigemini on the base of the greater wing of the sphenoid bone, and a small, posterolateral part of it extended in the major petrosal nerve canal hiatus of the temporal bone.

2. Ganglionic branches arose from the following vessels; the petrosal branch, the anastomotic ramus, the anastomotic artery, the middle meningeal artery, the accessory meningeal branch and the internal carotid artery, in order of the frequency. Of them, the first and the second were the main blood supply route, and the middle meningeal assisted it.

3. Ganglionic branches from various sources ramified into small arterial vessels, by some of which the supraganglionic and infraganglionic retia were formed in the capsule of the ganglion, and the others of which entered the ganglion from the forks between three divisions. Finally they spread into capillary networks, in one mesh of which one or two nervous cells were held.

In conclusion, the main route of the blood supply of the trigeminal ganglion in the dog was the extracranial blood source and in assistance of the intracranial. Communicating channels between both sources, the internal and external carotid systems, were the anastomotic ramus and artery as well as lots of multisource ganglionic branches.
\end{abstract}

\section{Preface}

It generally could be said that the trigeminal ganglion is situated between the distributing territories of the internal and external carotid arteries, and from which it is supplied a considerably rich blood. Accordingly, it is significant and interesting to investigate channels communicating between peripheral bran- ches of both carotid systems. There have been few of archives that concerned the blood supply of the ganglion in man, much less in mammals. Only a few of scholars who investigated the vasculature of the general nervous system have made short reports about that of the trigeminal ganglion. Meanwhile it has been described in textbooks that the ganglion of man was supplied with 
the internal carotid, the middle meningeal arteries, and the accessory meningnal branch. Baumel and Beard (1961) studied on the accessory meningeal artery of man and made a question, "What is the blood supply of the ganglion in the absence of an intracranial ramus?". Then he came to the conclusion that a limited number of dissections had been made on the available specimens with this in mind, and when intracranial rami of the accessory meningeal were lacking, direct branches of the intrasinus segment of the internal carotid passed to the ganglion were found, and these branches were the arteriae receptaculi, so further investigation along these lines was needed.

The present paper will deal with all distributing arterial vessels of the ganglion and their parent arteries in the dog, as the first step for the comparative angiology of it in mammals. The location of the ganglion of the dog, holding just between the external and internal carotid systems, is close to the anastomotic artery and the anastomotic ramus, by which both systems are connected. Consequently it is considered that a detailed and accurate investigation of distributing vessels of the dog ganglion will offer a key for the solution of the question given by Baumel et al., simultaneously a large and basic contribution for the comparative angiology of the carotid circulation. The present work will also deal with the fundamental structure of the ganglion of the dog because any works concerning it have not been seen so far.

\section{Materials and Methods}

Eighty-five adult dogs (about $10 \mathrm{~kg}$ weight) and five dry skulls were used for the observation.

On five heads of all the dogs the tri- geminal ganglion were extracted after surveying it and its surroundings, and fixed in absolute alcohol, embedded in celloidin, cut serially at $10 \mu \mathrm{m}$ and 100 $\mu \mathrm{m}$ thick, in the sagittal, horizontal or vertical direction of the ganglion, and stained with $1 \%$ cresil violet. By using this serial slide set, a wax-reconstruction model, magnified ten times, of nervous cell masses in the ganglion, was made. The other eighty heads were used for surveying the vasculature of the ganglion. Acryl plastic was injected through the common carotid arteries by means of the plastic injection method (Taniguchi, Ohta, Tajiri 1952, 1955). Eight of all the injected heads were fixed in formalin solution, two in absolute alcohol for dissection. Ganglions of three heads preserved in formalin and of two heads in alcohol were extracted after surveying the ganglion and its environs, those of the remaining five heads fixed in formalin were extracted with its surrounding structures, decalcified, embedded in celloidin, cut in three directions as mentioned above for a serial section of 10 $\mu \mathrm{m}$ and $250 \mu \mathrm{m}$ thick. The former, thinner slides were stained with hematoxylineosin or cresil violet; and the latter, thicker, non-stained, were used for surveying vessels in the ganglion and relations to cell masses. Remaining seventy injected heads were prepared to the corrosion specimens of the carotid system after digesting soft structures by sodium hydroxide solution. For observation and measurement of arterial vessels related, 121 sides of all the corrosions which were available to observe entirely ganglionic arterial branches without technical failures, were used. The binocular magnifier was employed for usual observation, and the scanning electron microscope (SUPER MINI-SEM MODEL MSM4S, AKASHI) for more details. Dry skulls were used for surveying the im- 
pressio trigemini and surrounding structures.

\section{Observations}

1. Form and location of the trigeminal ganglion (Fig. 1)

The trigeminal ganglion of the dog is flat and crescent (Figs. 4,5) in shape, $7 \sim 9 \mathrm{~mm}$ in length, $2 \sim 3 \mathrm{~mm}$ in width and $0.5 \sim 2 \mathrm{~mm}$ in height (highest in its medial end), facing the convexity of it anterolaterally (Figs. 3, 11).

Most part of the ganglion lies in the impressio trigemini (Fig. 2) of the cerebral surface of the base of the greater wing of the sphenoid bone, and the remaining small part in the major petrosal nerve canal hiatus (Miller 1964) (Fig. 3). The whole of the ganglion extends from the canal in the lateral side of the cavernous venous sinus to the tuberculum sellae anteromedially (Figs. 2, 3). The portio major connecting with the ganglion passes through the trigeminal canal (Fig. 2) at the apex of the petrous part of the temporal bone into a cavity, cavum trigeminale, pouched by the dura mater, in which the ganglion is covered by a capsule of the epineurium.

The ganglion is in relations with the internal carotid and the anastomotic arteries medially, the anastomotic ramus anteriorly, the middle meningeal artery laterally, and the petrous part of the temporal bone posteriorly, respectively (Figs. 1, 3).

Three divisions of the trigeminal nerve leave the convexity of the ganglion in three forks (Figs. 3,5). The ophthalmic nerve emerges anteriorly from the anterior end of it, the maxillary nerve anterolaterally and the mandibular nerve inferolaterally, while the portio major reaches the concavity, the posteromedial margin of the ganglion (Fig. 5). The ganglion consists of three cell groups; the ophthalmic, the maxillary and the mandibular (Figs. 4, 11). The first group, smallest, is in the shape of an elongated, anteroposteriorly, trigonal pyramid in the anterosuperomedial part of the ganglion. The second group is in the shape of a cone, facing its apex toward the foramen rotundum, and its basis, the radical side, appearing a recess in connection with the ophthalmic group, in the inferoanteromedial side of the ganglion. The third group is in the shape of an ovoid, in the posterolateral part of the ganglion closing to the maxillary group anteromedially, and its basis, the radical side, appearing a recess. And, the posterolateral extremity of this group becomes a tongue-like part which extends into the major petrosal nerve canal hiatus (Figs. 3, 5), and the anteromedial end of it is located on the center of a line connecting between the anterior margin of the foramen ovale and the same margin of the internal carotid foramen.

Each of three cell groups protrudes at the anterolateral end of the ganglion (Figs. 3,5 ). The maxillary group adheres to the mandibular group in the shape of a concave disc in the posteromedial end of it, from which the sensory radix emerges (Fig. 5). Through both convex (peripheral) and concave (central) sides, the epineurium from the capsule of the ganglion, trabecula-shaped, invades between the cell groups, then continues as the perineurium within the cell group. The respective cell group consists of cell masses which show somewhat radical arrangement from anterior to anterolateral hoding nervous bundles between them (Fig. 4). The portio minor of the trigeminal nerve passes from inferomedial to anterolateral, adhering closely to the inferior surface of the portio major, and turns onto the inferior surface 


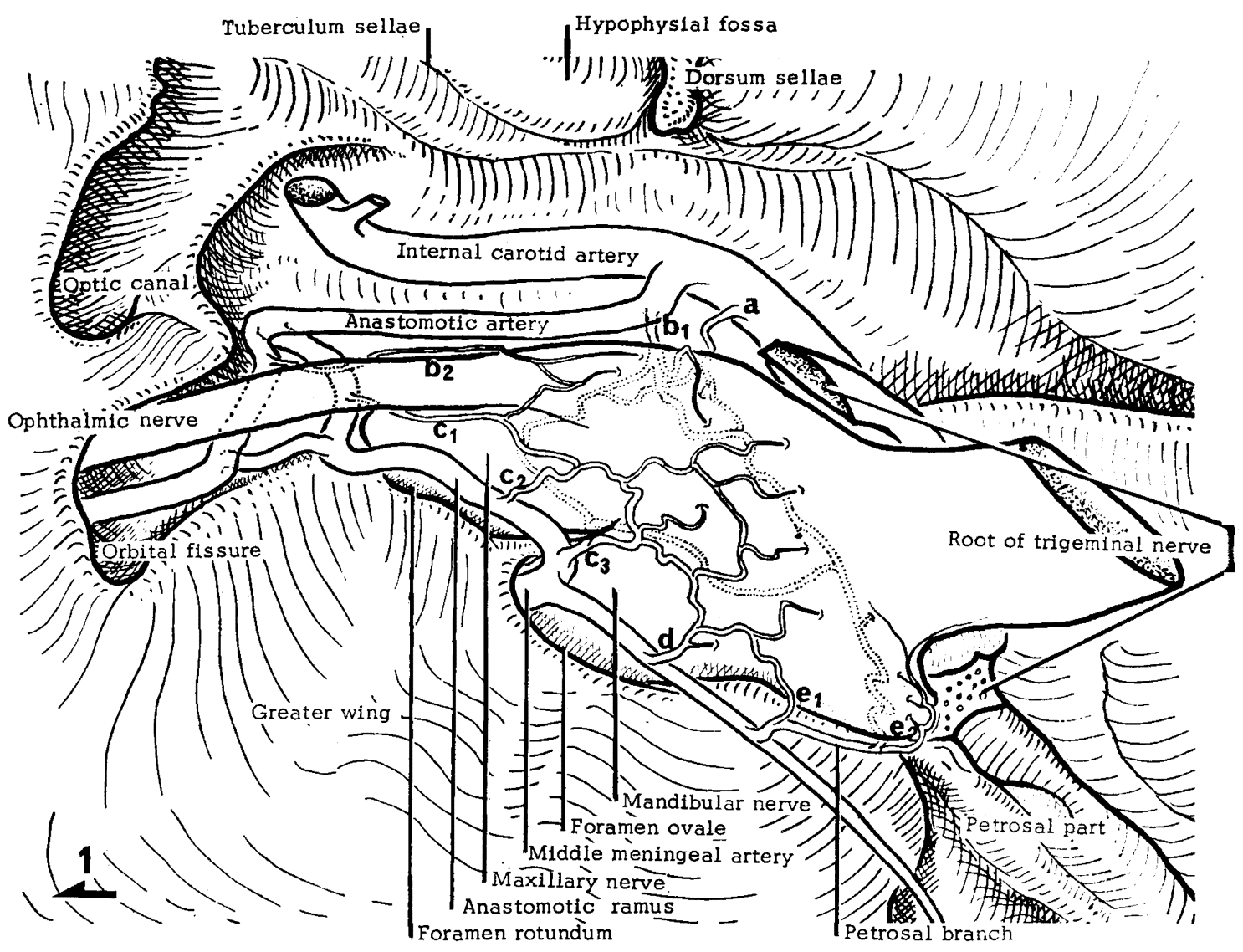

Fig. 1. The schematic illustration of the blood supply of the trigeminal ganglion of the dog. The major petrosal nerve canal hiatus and the upper wall of the trigeminal canal (*) were removed. The supraganglionic rete is indicated by a solid line and the infraganglionic rete by a dotted line.

Letters in this figure indicate ganglionic branches arising from the following arteries:

a: from the internal carotid artery.

$b_{1}$ : from the anastomotic artery, immediately before the communication with the internal carotid.

$\mathrm{b}_{2}$ : from the anastomotic artery, immediately after the entrance through the orbital fissure into the cranial cavity.

$c_{1}$ : from the anastomotic ramus, inferior to the ophthalmic nerve.

$c_{2}$ : from the anastomotic ramus, lateral to the maxillary nerve.

$c_{3}$ : from the anastomotic ramus, at the fork between the maxillary and the mandibular divisions.

d: from the middle meningeal artery, lateral to the mandibular nerve.

$e_{1}$ : from the petrosal branch, lateral to the mandibular nerve.

$\mathrm{e}_{2}$ : from the petrosal branch, at the major petrosal nerve canal hiatus. 
between the maxillary and the mandibular groups (Fig. 5), then runs inferolaterally along the anteromedial side of the mandibular nerve, and finally leaves the cranial cavity through the anteromedial margin of the foramen ovale.

2. Distributing arteries of the trigeminal ganglion (Fig. 1)

Trigeminal ganglionic branches diverge from the following arteries; the petrosal branch, the anastomotic ramus, the anastomotic artery, the middle meningeal artery, the accessory meningeal branch and the internal carotid artery.

Of all ganglionic branches, those of the petrosal branch and the anastomotic ramus are main vessels, and the former is supplemented by those of the middle meningeal artery (Figs. 6, 12, 14) and the latter is supplemented by those of the anastomotic artery if it is very weak. Those of the anastomotic artery are supplemented by those of the internal carotid if they are weak or defective (Fig. 8). When the middle meningeal enters the cranial cavity through any opening except the anterior margin of the foramen ovale or rotundum, the ganglionic branch of the artery is not observed (Figs. 8, 15). In these cases, the accessory meningeal is present, the ganglionic branch of it or the petrosal branch is well-developed (Fig. 11). If the ganglionic branch of the anastomotic ramus is well-developed, that of the anastomotic artery is less-developed or even defective (Figs. 6, 14).

All these ganglionic branches arrive at the capsule of the ganglion (Fig. 16). Destination of them is not in irregular, but in most cases the fork between the maxillary and the mandibular divisions, the posteromedial end of the ganglion and the tongue-like part of it, and additionally the fork between the ophthalmic and the maxillary. Each of the branches spreads into $2 \sim 4$ in the capsule, and some of them directly enter the ganglion and the others form arterial networks on both superior and inferior surfaces of it, named the supraganglionic rete and the infraganglionic rete (Figs. $16,18)$. Component vessels of it meander strongly and communicate richly with those of adjacent territories.

1) Ganglionic branches arising from the petrosal branch.

The petrosal branch, seen in 114 cases of all 121 examples observed, arises from the middle meningeal (73 cases, Figs. 12, 13 ), the anastomotic ramus (33 cases, Figs. $7,8,15)$ and the accessory meningeal branch (8 cases) posteriorly. The stream of the branch turns almost into ganglionic branches (Fegs. 7, 13).

They (72 168, M. $120 \mu \mathrm{m}$ in diameter) are $3 \sim 6$ in number ( 3 in 28 cases, 4 in 36 cases, 5 in 33 cases, 6 in 17 cases). Differences in number are according to the location of various origins of the parent vessels as mentioned above; largest of the anastomotic ramus and smallest of the middle meningeal. The branch arises at the following positions :

(i) The ganglionic branch arising at the anterior margin of the mandibular nerve.

The branch is observed in all the 41 cases in which the petrosal arises from the anastomotic ramus (Fig. 7) or the accessory meningeal (Fig. 13), as well as in 15 cases of the 73 cases in which it arises from the middle meningeal. It, one or two in number (one in 39 cases and two in 17 cases), arises immediately after the origin of the petrosal, and runs medially on the anterior margin of the mandibular nerve, then turns into several twigs which enter the ganglion through the fork between the maxillary and the mandibular divisions for supplying these cell groups, also participate in the supra- and infraganglionic retia. 
(ii) The ganglionic branch arising at the lateral side of the mandibular nerve.

The branches, $1 \sim 3$ in number (one in 12 cases, two in 23 cases, three in 21 cases), are observed in the same cases mentioned in i) (Figs. 7, 13, 14, 15), smallest in diameter among them arising from the petrosal, arise from it when it runs posteriorly at the lateral side of the mandibular nerve. It passes medially and spreads into $1 \sim 3$ which supply the mandibular cell group and participate in the supraganglionic rete.

(iii) The ganglionic branch arising in the major petrosal nerve canal hiatus.

The petrosal branch passes posteriorly toward the canal hiatus where it spreads ganglionic branches anteromedially, 2 4 in number in the 114 cases (two in 63 cases, three in 29 cases, four in 22 cases) (Figs. 8, 12). They, largest in diameter, supply almost all blood of the parent vessel to the ganglion, meandering frequently down to the posterolateral end, that is, the tongue-like part of it. Some of them directly enter it for supplying the mandibular cell group, and the others participate in the infraganglionic rete (Figs. 9,10 ) or sometimes only enter the ganglion for supplying the mandibular cell group.

2) Ganglionic branches arising from the anastomotic ramus.

The anastomotic ramus, seen in 111 cases of all 121 examples observed, arises from the middle meningnal artery in 94 cases (Figs. 12, 13, 14), from the accessory meningeal branch in 8 cases on the anterior margin of the foramen ovale, and directly from the maxillary in 9 cases (Figs. 8, 15). It enters the cranial cavity through the anterior margin of the foramen ovale or the posterior margin of the foramen rotundum.

Ganglionic branches (68 260, M. 145 $\mu \mathrm{m}$ in diameter), $1 \sim 6$ in number (one in 16 cases, two in 28 cases, three in 23 cases, four in 26 cases, five in 14 cases and six in four cases), arise from the anastomotic ramus at the following positions :

(i) The ganglionic branch arising at the anterior margin of the foramen ovale.

The branch, one in 79 cases of the 111 cases, arises from the inferior or inferomedial wall of the anastomotic ramus at the anterior margin of the foramen ovale (Figs. 6, 7, 12) immediately after the origin of it, and divides into $3 \sim 5$ at the fork between the maxillary and the mandibular divisions. One or two of them participate in the supraganglionic rete, and the others enter the ganglion through the fork mentioned above to supply the maxillary cell group, or sometimes participate in the infraganglionic rete.

(ii) The ganglionic branch arising at the lateral side of the maxillary nerve.

The branches, two or three in number in 52 cases of the 111 cases (two in 22 cases and three in 30 cases), arise posteriorly from the superomedial wall of the anastomotic ramus when it runs anteromedially along lateral to the maxillary nerve (Figs. 8, 13, 14) and continue posteriorly superior to the nerve to join the supraganglionic rete.

(iii) The ganglionic branch arising at the inferior side of the ophthalmic nerve.

The anastomotic ramus communicates with the anastomotic artery after crossing inferior to the ophthalmic nerve medially (Figs. 3, 7). The ganglionic branches, two or one in number in 71 cases of the 111 cases (two in 57 cases and one in 14 cases), arise from the superior wall of the anastomotic ramus (Figs. 6,7) at this point and run posteriorly along the inferior or inferolateral side of the ophthalmic nerve down to the fork between this and the maxillary divisions, and finally divides into. 
two or three. They participate in the supra- and infraganglionic retia, also enter directly the ganglion to supply the cell groups mentioned above.

3) Ganglionic branches arising from the anastomotic artery.

The anastomotic artery leaves the external ophthalmic or the orbital artery and enter the cranial cavity through the orbital fissure after running along the inferolateral side of the ophthalmic nerve and passes medially across the inferior side of it to communicate with the anastomotic ramus (Fig. 1). The ganglionic branch (48 552, M. $199 \mu \mathrm{m}$ in diameter), 1 3 in number (one in 52 cases and two in 13 cases and three in 4 cases', seen in 69 cases of all 121 examples observed, arises at the following positions:

(i) The ganglionic branch arising immediately after the entrance of the anastomotic artery into the cranial cavity.

The branch, one in 13 cases of the 69 cases, arises from the superior or lateral wall of the artery when it bends posteriorly after crossing the ophthalmic nerve (Figs. 8, 11, 12). It runs posteriorly along the medial side of the nerve down to the anteromedial end of the ganglion, and finally spreads into twigs which enter the ganglion to supply the ophthalmic and the maxillary cell groups, also participate in the supra- and infraganglionic retia.

(ii) The ganglionic branch arising immediately before the communication between the anastomotic and the internal carotid arteries.

The branch, one or two in number, in the 69 cases (one in 52 cases and two in 17 cases . arises from the posterolateral wall of the anastomotic artery immediately before the communication with the internal carotid (Figs. 12, 13). It runs laterally between the oculomotor and the abducent nerves, giving twigs to them, toward the posteromedial end of the ganglion, and finally spreads into three to five. Some of them enter directly the ganglion to supply the ophthalmic and the maxillary cell groups, and the others participate in the supraand infraganglionic retia after running superoanteriorly or inferoposterolaterally along the medial margin of it.

4) Ganglionic branches arising from the middle meningeal artery.

The artery, in 118 cases of all 121 examples observed, arises from the superior wall of the maxillary artery, and enters the cranial cavity through the anterior margin of the foramen ovale (in 95 cases, Figs. $7,12,13$ ), the foramen spinosum (in 10 cases, Fig. 8 , the foramen rotundum (in 6 cases, Fig. 14), the superior wall of the auditory canal (in 6 cases), or the posterior margin of the foramen ovale (in one case, Fig. 11). In three cases, the artery arises from the anastomotic artery (Fig. 15. The ganglionic branch $(72 \sim 480$, II. $168 \mu \mathrm{m}$ in diameter), one to three in number. is seen in 47 cases of the 101 cases, in which the middle meningeal passes through the anterior margin of the foramen ovale or rotundum.

(i) The ganglionic branch arising from the middle meningeal artery which passes through the anterior margin of the foramen ovale.

The middle meningeal passes through the anterior margin of the foramen ovale into the cranial cavity, and immediately bends posteriorly along the lateral margin of the mandibular nerve down to the posterolateral end of the ganglion. On this course ganglionic branches arise from the artery before the origin of the petrosal branch. They are seen $1 \sim 3$ in number in 44 cases (one in 37 cases, two in 6 cases and three in one case) of the 95 cases. Some of them arising from the medial wall at the anterior margin of the mandibular nerve spread into 
small twigs at the fork between the maxillary and the mandibular divisions (Figs. 12, 13), and enter the ganglion for supplying these cell groups, also participate in the supra- and infraganglionic retia, and the others arising at the lateral side of the nerve participate in the supraganglionic rete (Fig. 6). Additional branches arising from the inferior wall pass medially and spread into small twigs at the fork of the divisions for supplying the maxillary cell group, also for participating in both retia.

(ii) The ganglionic branch arising from the middle meningeal artery which passes through the foramen rotundum.

The middle meningeal passes through the lateral margin of the foramen rotundum into the cranial cavity, and immediately bends posteriorly to continue along the lateral side of the maxillary nerve. The branch, seen only in three cases (one in two cases and two in one cases) of the six cases, arises posteromedially from the inferior wall of the artery at the fork between the maxillary and the mandibular divisions (Fig. 14). It immediately spreads into $2 \sim 4$, which directly enter the ganglion to supply these cell groups and participate in the supra- and infraganglionic retia.

5) Ganglionic branch arising from the accessory meningeal branch.

The accessory meningeal arises from the maxillary (in 12 cases, Fig. 11) or the middle meningeal (in three cases). It, in 8 cases of the 15 cases, trifurcates into the anastomotic branch anteromedially, the petrosal branch posteriorly and the ganglionic branch medially. The ganglionic branch (144 480, M. $246 \mu \mathrm{m}$ in diameter) immediately spreads into two to four which directly enter the ganglion through the fork between the maxillary and the mandibular divisions for supplying the maxillary cell group, also for participating in both supra- and infraganglionic retia. The ganglionic branch in seven cases of the 15 cases enters the cranial cavity and immediately spreads into small twigs (Fig. 11) which enter the ganglion for supplying the maxillary and the mandibular cell groups and participate in both retia.

6) Ganglionic branch arising from the internal carotid artery.

The branch $(168 \sim 408$, M. $280 \mu \mathrm{m}$ in diameter), seen in 6 cases of all 121 examples observed, arises laterally from the inferolateral wall of the internal carotid, proximal to the communication between it and the anastomotic artery (Fig. 8). It passes laterally between the oculomotor and the abducent nerves for about $1 \mathrm{~mm}$ in the cavernous venous sinus down to the posterolateral end of the ganglion, and spreads into three to five. Some of them enter the granglion directly for supplying the maxillary cell group, and the others run inferoposterolaterally for participating in the infraganglionic rete, or anteriorly along the medial margin of the ganglion for joining the supraganglionic rete and for supplying the ophthalmic cell group.

3. Arterial supply in the trigeminal ganglion

Ganglionic branches which have taken their courses from various sources mentioned above onto the capsule of the ganglion, ramify into small twigs in two groups; for participating in a formation of arterial networks on the superior and inferior surfaces of the ganglion, the supra- and infraganglionic retia, and for entering directly the ganglion to supply cell groups.

1) Supraganglionic and infraganglionic retia (Fig. 1)

Among component vessels of the supraganglionic rete, a main trunk is always observed. It passes anteromedi- 
ally from the posterolateral side of the mandibular nerve along the lateral margin of the ganglion (Fig. 6) to the ophthalmic nerve via the superior side of roots of the mandibular and the maxillary nerves. It communicates with the following ganglionic branches; of the petrosal branch arising at the lateral side of the mandibular nerve, and of the same branch coming to the fork between the maxillary and the mandibular divisions, or of the anastomotic branch, or of the middle meningeal coming to the fork mentioned above, and of the anastomotic ramus coming to the lateral side of the maxillary nerve, sometimes coming to the lateral side of the ophthalmic nerve. During the rich communication between these vessels coming from various sources, small twigs are derived posteromedially from the main trunk, and meander, ramify many times, communicating with adjacent fellows, and finally become forming the supraganglionic rete (Fig. 6).

A main trunk is also seen in the infraganglionic rete (Fig. 8). It passes from the tongue-like part of the ganglion in the major petrosal nerve canal hiatus to the posteromedial end of the ganglion along the convexity of it, and communicates with the ganglionic branch of the petrosal branch entering the tongue-like part and with those of the internal carotid or the anastomotic arteries coming to the medioposterior end of the ganglion. From the main trunk, many small twigs diverge anterolaterally and participate in the infraganglionic rete, after ramifying and anastomosing with adjacent fellows many times, in assistance of the ganglionic branch coming to the forks between three divisions, while some of them pass posteromedially to supply the trigeminal radix (Fig. 7). Finally, smaller twigs arising from the rete enter the ganglion (Figs. 10, 16).

\section{2) Intraganglionic arterial vessels}

Vessels (40 85, M. $67 \mu \mathrm{m}$ in diameter) come into the ganglion through the epineurium in the shape of trabecula, which continues from the capsule of the ganglion (Fig. 8). They meander postero- or anteromedially among nervous cell groups in the epineurium, then spreads into smaller (15 55, M. $27 \mu \mathrm{m}$ in diameter) arborescently toward the perineurium (Figs. 18, 19). They usually arise from three sources as follows: The first, small (20 60, M. $38 \mu \mathrm{m}$ in diameter), comes from the supra- and infraganglionic retia and arrives directly at the perineurium, immediately supplies the cell masses; The second comes posteriorly without via the retia and enters the ganglion through the forks between three divisions in the convexity of it, and meandering, gives rise to lots of twigs posteromedially after running across any of three divisions (Figs. 8, 17), and the third comes anteriorly without via the retia and enters the ganglion in the concavity of it through the tongue-like part of the major petrosal nerve canal hiatus and the posteromedial end of the ganglion (Fig. 10), and meandering along the concavity of it, gives rise to lots of twigs anterolaterally (Figs. 8, 17). In addition to these vessels, arterial vessels $(20 \sim 65, \mathrm{M}$. $36 \mathrm{um}$ in diameter) running along the concavity of the ganglion give rise to small twigs posteromedially which supply the portio major, also vessels running along the convexity of it to small twigs which supply all three divisions (Fig. 17).

Generally small twigs in the perineurium seldom communicate with one another, but those in the epineurium do richly (Fig. 10). Those in the perineurium furthermore spread into smaller (8 15, M. $11 \mu \mathrm{m}$ in diameter), which invade into cell masses of each cell 
group. Finally they develop into capillary networks, in one mesh of which one or two nervous cells are held (Figs. $18,19)$.

\section{Discussion}

On the position of the trigeminal ganglion of the dog, Miller (1964) stated that the semilunar-shaped ganglion was located in the cavum trigeminale of the dura mater lateral to the cavernous sinus at the apex of the petrous temporal bone, as it has been mentioned about that of man. The present author, however, made obvious findings that most of the ganglion of the dog lay in the impressio trigemini of the cerebral surface of base of the greater wing of the sphenoid bone, and the remaining small, tongue-like part in the major petrosal nerve canal hiatus. The impressio of man was located on the superior surface of the petrous portion of the temporal bone, but that of the dog appeared to be a canal, through which the trigeminal radix passed, medial to the foramen ovale in the base of the greater wing.

Ferner (1939) described that the ganglionic cells of man were arranged in irregularly radical groups for each division of the trigeminal nerve and the nervous bundles were led through them. In the present paper, such an arrangement shown by Ferner was also made clear by means of observing the waxreconstruction model of the ganglion in the dog. Simultaneously, arterial vessels entering the ganglion have passed being accompanied with the trabecula-shaped epineurium from the capsule of the ganglion.

There have not been any archives which investigated the blood supply of the trigeminal ganglion of mammals. Bartholody (1897) and Grigorowsky (1928), in their works which surveyed the arterial distribution of the general nervous system of man, stated that the trigeminal ganglion was supplied with the aa. sinus cavernosi of the internal carotid, the middle meningeal and the accessory meningeal branch. Lazorthes (1971) wrote a book concerning the peripheral nervous system and cited the original illustration drawn by Libersa of the vascularisation of the trigeminal ganglion of man. Adams (1942) stated, in his historical review of the blood supply of the nervous system of man, that the trigeminal ganglion of man in the description of Tanassesco (1905) was supplied with the ganglionic branch of the internal carotid, but the branch had no communication with the middle meningeal or the accessory meningeal. Ferrari et Ribet (1927) and Stöhr (1928) described that only a branch of the internal carotid was distributed to the ganglion in man. In some of textbooks of human anatomy, such as by Rauber-Kopsch (1955), Kamijio (1966), Hirasawa (1969) and Gray's (1973), the ganglion of man was mostly supplied blood from the internal carotid, the middle meningeal and the accessory meningeal.

The ganglion of the dog has received blood from six arterial sources; the internal carotid, the middle meningeal, the accessory meningeal branch as seen in man, and in addition to them the anastomotic artery, the anastomotic ramus and the petrosal branch which were not seen in man. Ganglionic branches of the middle meningeal artery were seen in 39 percent of all examples observed, those of the anastomotic ramus (arising from the middle meningeal) in 92 percent and those of the petrosal branch in 94 percent. According to the frequency, the parent vessels mainly were the anastomotic and the petrosal branches almost in all examples, in assistance of 
that of the middle meningeal. When the petrosal branch left the middle meningeal, the posterior the origin moved, the narrower the distributing territory became. On the contrary, ganglionic branches of the artery became stronger and the territory became wider. When the petrosal branch left the anastomotic ramus locating anterior to the origin of the middle meningeal, the ganglionic branch of the petrosal was always strong and the distributing territory was wide. Detailed observations on various features of the entrance of the middle meningeal through any openings except the foramen ovale into the cranial cavity, were already reported by Okuda et al. (1974). When the artery passed through the foramen spinosum, the ganglionic branch of the accessory meningeal supplied the ganglion instead of that of the artery. The ganglionic branch of the middle meningeal in man was described by Bartholody and Grigorowsky. In the textbook of Gray's anatomy, the ganglion and radix were supplied with numerous small ganglionic branch. Baumel and Beard (1961) made a report that a branch of the accessory meningeal passed through the foramen ovale and supplied the ganglion in man. Descriptions on the ganglionic branch of the accessory meningeal have been made in the textbook mentioned above and in works by Lazorthes, Bartholody and Grigorowsky. In conclusion the ganglionic branch in man arose from the middle meningeal in few cases but rather from the accessory meningeal in most cases. In the present work, the accessory meningeal in the dog played an important role in the sources of the ganglionic branch in some cases in which the middle meningeal passed through the foramen spinosum. In these cases the ganglionic branch of the middle meningeal was not observed.
The anastomotic ramus and the anastomotic artery and the ganglionic branch of them were reported by Jewell (1952) and Furuhara (1974). As described in the present observations, the anastomotic ramus, most important blood source for the ganglion, was a communicating vessel between the internal and external carotid systems; actually between the middle meningeal and the anastomotic artery, or sometimes between the latter and the maxillary artery. Ganglionic branches of the ramus mainly entered the ganglion around the maxillary nerve because it passed along the convexity of the ganglion. If the ganglionic branch of the ramus was less-developed, the blood supply was supplemented by that of the anastomotic artery, but when the former was well-developed, the latter was not observed often. Especially the ganglionic branch arising immediately after the entrance of the anastomotic artery into the cranial cavity was apt to disappear. When the ganglionic branch of the internal carotid was seen, the ganglionic branch arising, immediately before the communication with the internal carotid, of the anastomotic artery, was less-developed. Generally ganglionic branches of the internal carotid and the anastomotic arteries were defective in many cases. But, the ganglionic branch of the internal carotid in man has been reported by the previous workers; cavernous branches of it were distributed to the ganglion, especially described in Gray's Anatomy. Anderson et al. (1971) stated that a trigeminal artery in the dog arose from the basial or the superior cereberal artery unilaterally or bilaterally and ran, meandering, across the pons laterally between the sensory and motor radices of the trigeminal nerve. Such an artery was observed in the present work, but was not distributed to the ganglion itself. 
Peripheries of all ganglionic branches had rich anastomoses throughout the supra- and the infraganglionic arterial retia in the capsule of the ganglion. It could be said that the anastomoses were the communication between many blood sources. Arterial vessels passing in the epineurium from the capsule spread into smaller twigs to pass in the perineurium, but the former did not differ from the latter in thickness. These vessels still made anastomoses both in the epineurium and perineurium.

\section{Acknowledgement}

The author expresses his sincere thanks to Professor Y. Ohta for critical reading of the manuscript, also Assistant Professor T. Tokioka and all staff members of the Department of Anatomy for their great assistance shown to him.

\section{References}

1) Adams, W.E.: The blood supply of nerves. J. Anat., 76: 323-341, 1942.

2) Anderson, W.D. and W. Kubicek: The vertebral-basilar system of dog in relation to man and other mammals. Am. J. Anat., 132 : 179-188, 1971.

3) Bartholody, K.: Die Arterien der Nerven. Morph. Arb., 7 : 393-458, 1897.

4) Baumel, J.J. and D.Y. Beard: The accessory meningeal artery of man. J. Anat., 95 : 386-402, 1961.

5) Ferner, H.: Über den Bau des Ganglion semilunare (Gasseri) und der Trigeminuswurzel beim Menschen. Z. Anat. u. Entw., 110: 391-404, 1939.

6) Ferrari and Ribet: Trav. Lab. anat. Med., Anat. Ber. 29, (cited by Adams), 1927.

7) Furuhara, H.: On the middle meningeal artery of the dog, referred to its origin and the r. anastomoticus. Okajimas Fol. anat. jap., 51 : 231-250, 1974.

8) Grigorowsky, I.M.: Zur Anatomie der die Kopfnerven ernährenden Arterien. Z. Anat. u. Entw., 87 : 728-740, 1928.

9) Hirasawa, K. and M. Okamoto: Anatomy, II. Angiology, 10th ed., Kanehara co., Tokyo, 1976. (in Japanese)

10) Jewell, P.A.: Anastomoses between internal and external carotid circulations in the dog. J. Anat., 86: 83-94, 1952.

11) Kamijo, Y.: Oral anatomy, III. Angiology, 1st ed., Anatom co., Tokyo, 1966. (in Japanese)

12) Kopsch, F.R.: Lehrbuch und Atlas der Anatomie des Menschen. Georg Thieme, Stuttgart, 1955.

13) Lazorthes, G.: Le systeme nerveux peripherique description-systematisation ex ploration. Masson et C. Paris. 78 and 79, 1971.

14) Miller, M.H., G.C. Christensen and H.E. Evans: Anatomy of the dog. W.B. Saunders, Phila., 6-856, 1964.

15) Okuda, H., T. Tokioka and H. Furuhara: On the relationship between the foramen spinosum and middle meningeal artery of the dog. Okajimas Fol. anat. jap., 51 : 91-102, 1974.

16) Stöhr, Ph. Jr.: v. Möllendorff's Hb. d. mikros. Anatomie d. Menshen. Bd. 4-1, 213, Berlin. 1928.

17) Tanasesco, J.C.: Bull. Mem. Soc. Anat. 80, 834. (cited by Adams), 1905.

18) Taniguchi, Y., Y. Ohta and S. Tajiri: New improved method for injection of acrylic resin. Okajimas Fol. anat. jap., 24 : 259-267, 1952.

19) Taniguchi, Y., Y. Ohta, S. Tajiri, H. Okano and H. Hanai: Supplement to new improved method for injection of acrylic resin. Okajimas Fol. anat. jap., 27: 401-406, 1955.

20) Warwick, R. and P.L. Williams: Gray's anatomy, 35th ed., Longman, London, 1973. 


\section{PLATES}

\section{Key to abbreviations}

MX: Maxillary nerve

NM : Mandibular nerve

NO: Ophthalmic nerve

NT: Trigeminal nerve

0 : Orbital fissure

OV: Foramen ovale

P: Petrosal part of the temporal bone

$\mathrm{R}$ : Foramen rotundum
W: Greater wing

aa: Anastomotic artery

ar: Anastomotic ramus

ic: Internal carotid artery

$\mathrm{m}$ : Maxillary artery

$\mathrm{mm}$ : Middle meningeal artery

p: Petrosal branch

$\Rightarrow$ Direction of the snout 


\section{Explanation of Figures}

\section{Plate I}

Fig. 2. The superior view of the middle cranial fossa. The upper wall of the trigeminal canal of the left side was removed to show the impressio trigemini on the base of the greater wing of the sphenoid bone. The whole outline of the trigeminal ganglion is indicated by a dotted line. Tuberculum sellae $(*)$, major petrosal nerve canal hiatus $(\searrow$ ), trigeminal canal $(\uparrow)$, hypophyseal fossa $(O)$, dorsum sellae $(\triangle)$, grooves for the middle meningeal artery $(\swarrow)$ and for the internal carotid $(x)$. $x$ ca. 4.

Fig. 3. The superior view of the trigeminal ganglion of the left side. Upper walls of the trigeminal canal and the major petrosal nerve canal hiatus were removed to show three divisions of the trigeminal nerve and arteries in relateon with the ganglion. Outline of the ganglion is indicated by a dotted line. Tuberculum sellae $(\uparrow)$, the tongue-like part of the ganglion $(\downarrow)$, dorsum sellae $(\Delta) . \quad \times$ ca. 6 . 
Plate 1

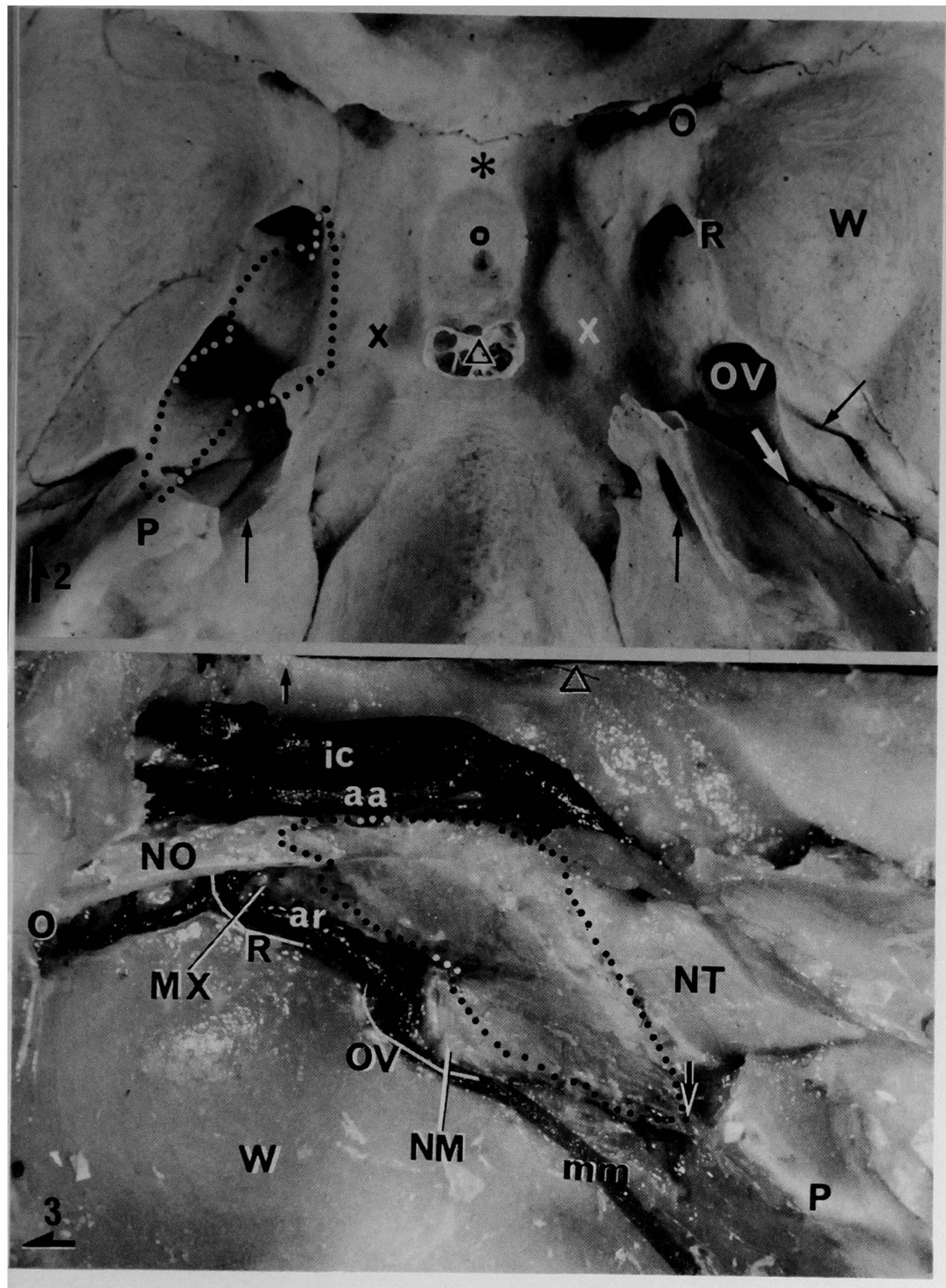

H. Okuda 


\section{Plate II}

Fig. 4. The horizontal section of the ganglion of the right side in the height between the ophthalmic and the mandibular cell groups, superior to the maxillary cell group. They are placed from the anterior to the posterolateral, and the posterolateral extremity of the mandibular group becomes the tongue-like part $(\uparrow)$. Each group consists of smaller cell masses $(\downarrow) . \quad \times$ ca. 11 .

Fig. 5. The inferomedial view of a wax-reconstruction model of cell groups of the trigeminal ganglion of the left side. A shallow notch for the portio minor $(\rightarrow)$. The tongue-like part of the mandibular group $(\uparrow) . \times$ ca. 10 .

Fig. 6. The superolateral view of the ganglion of the left side. Ganglionic branches are welldeveloped; a branch $(\square)$ lateral to the maxillary nerve and two branches $(O)$ inferior to the ophthalmic nerve. The petrosal branch arises from the middle meningeal at the posterolateral end of the ganglion and runs posteriorly in the major petrosal nerve canal hiatus (*) after supplying the ganglion. The middle meningeal gives rise to two ganglionic branches $(\Delta)$ proximal to the origin of the petrosal branch. A main trunk $(\uparrow)$, communicating with the ganglionic branches mentioned above, is seen in the anterolateral part of the ganglion, and gives rise to small twigs which form the supraganglionic rete. In this specimen, neither ganglionic branches of the internal carotid, nor of anastomotic artery are seen. $\times$ ca. 7 . 
Plate II

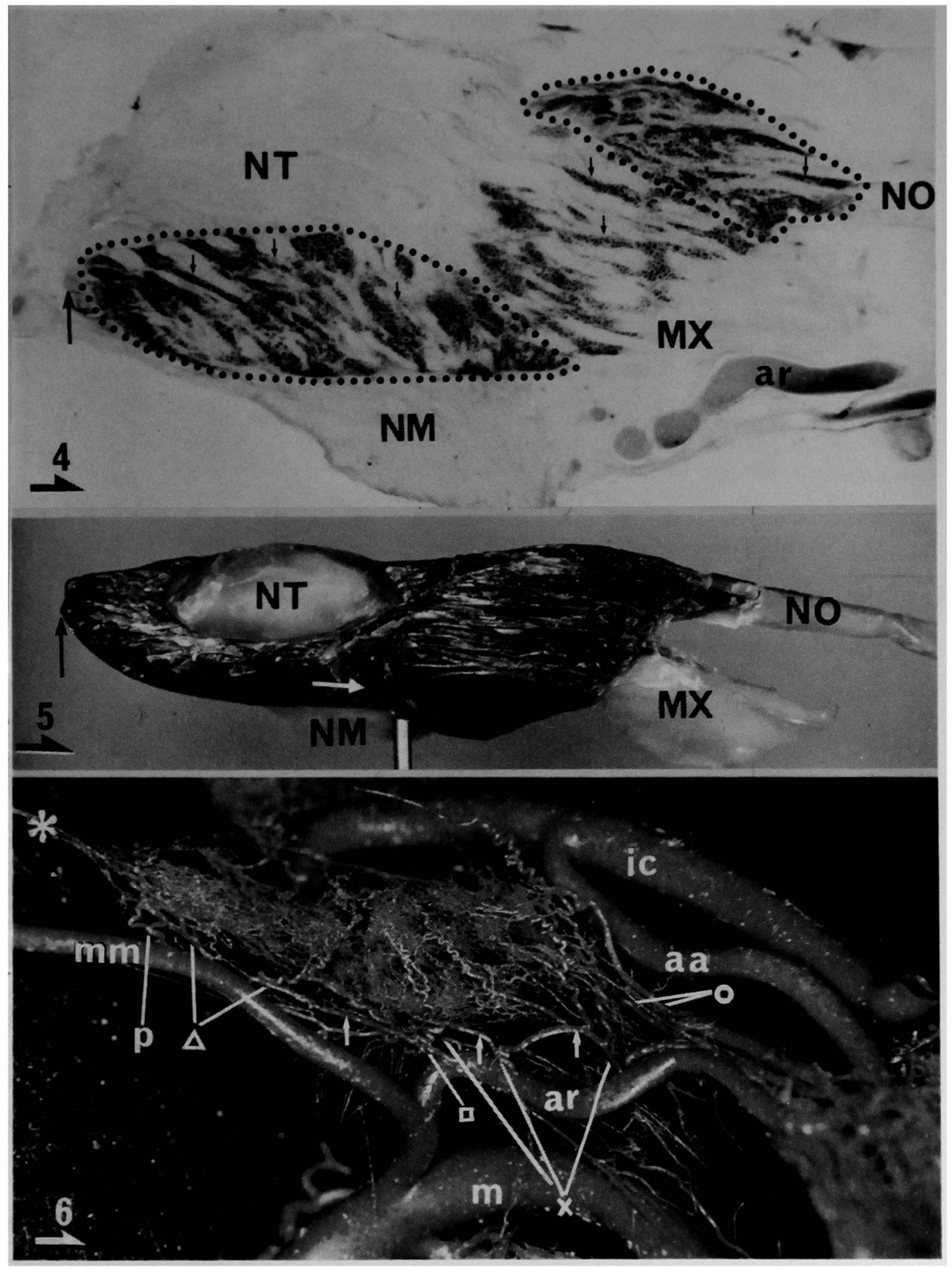

H. Okuda 


\section{Plate III}

Fig. 7. The superolateral view of the ganglion of the left side. The petrosal branch arising from the anastomotic ramus gives off a ganglionic branch at the anterior margin of the mandibular nerve $(*)$, three branches lateral to it $(\uparrow)$ and two branches $(\leftarrow)$ at the tongue-like part. The ramus gives off a ganglionic branch $(\triangle)$ at the anterior margin of the mandibular nerve, two branches $(x)$ lateral to the maxillary nerve, a branch $(O)$ inferior to the ophthalmic nerve. A main trunk $(\downarrow)$ in the infraganglionic rete gives off small twigs for supplying the trigeminal radix $(\rightarrow)$. In this specimen, neither ganglionic branches of the internal carotid, nor of the anastomotic, nor of the middle meningeal artery are seen. $\times$ ca. 8.

Fig. 8. The superolateral view of the ganglion of the left side. The middle meningeal passes through the foramen spinosum (C) into the cranial cavity, but does not give off the ganglionic branch. The anastomotic ramus arising from the maxillary artery gives rise to the petrosal branch at the anterior margin of the foramen ovale. The branch gives off two strong ganglionic branches $(\leftarrow)$ at the tongue-like part. Two ganglionic branches $(x)$ of the ramus are so fine that they are supplemented by those of the internal carotid $(\triangle)$ and the anastomotic arteries $(O)$. A main trunk $(*)$ in the infraganglionic rete communicates between ganglionic branches of the internal carotid and of the petrosal branch at the posteromedial margin of the ganglion. In the ganglion, an arterial vessel runs across three nervous divisions in the convexity of it $(\uparrow)$ and the other $(\downarrow)$ along the concavity (cf. Fig. 17). $\times$ ca. 6.5. 
Plate III

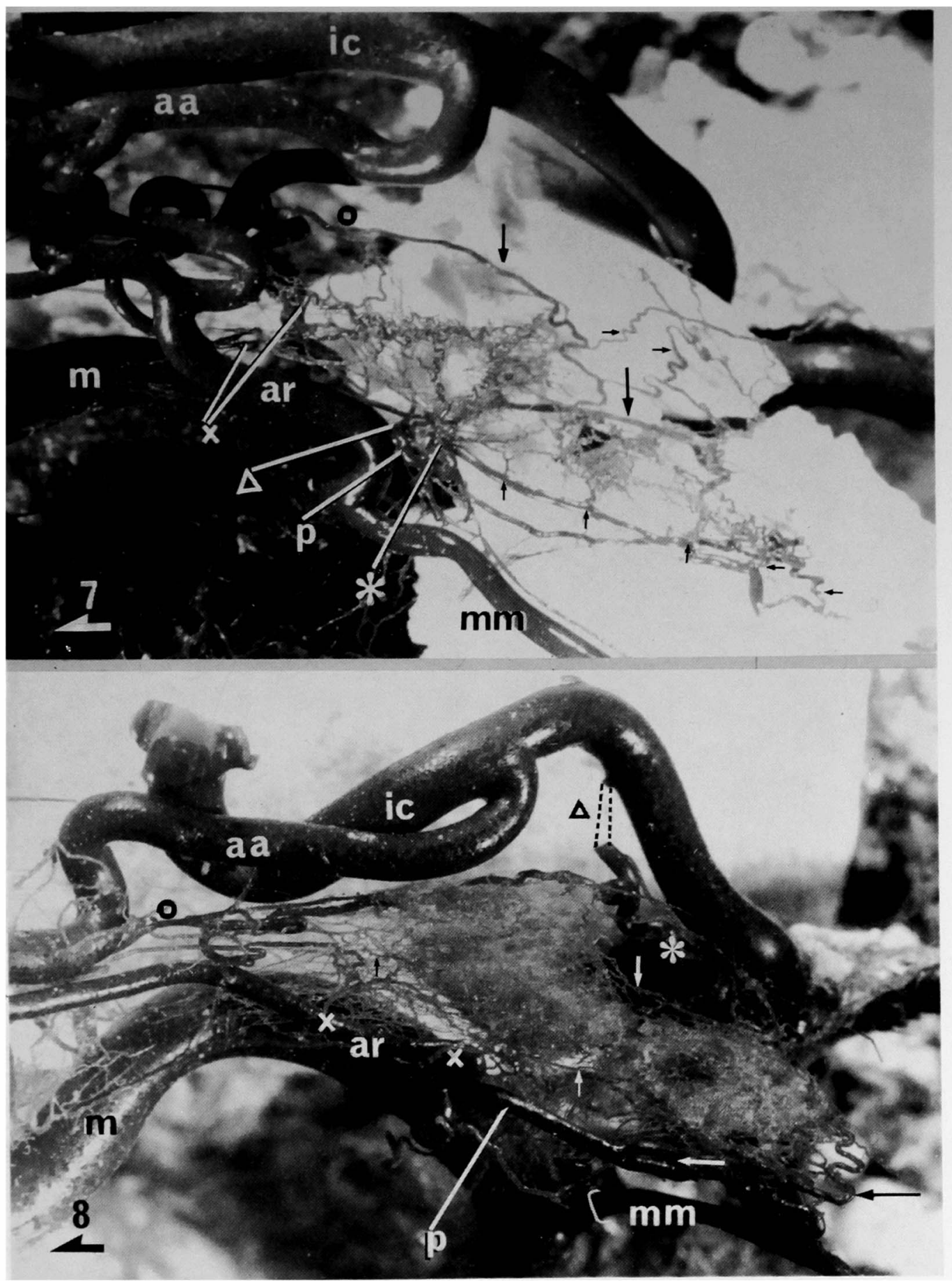

H. Okuda 


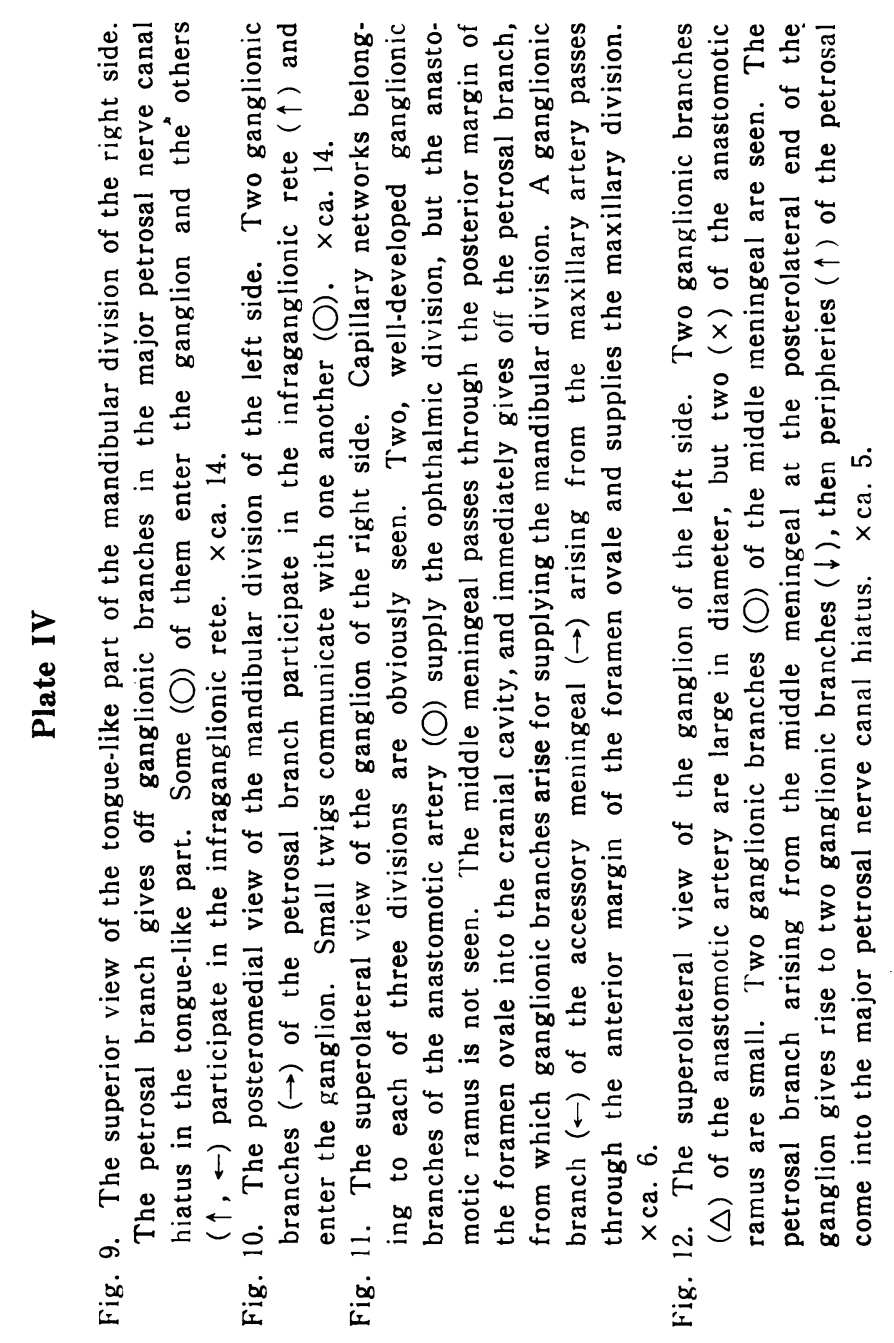




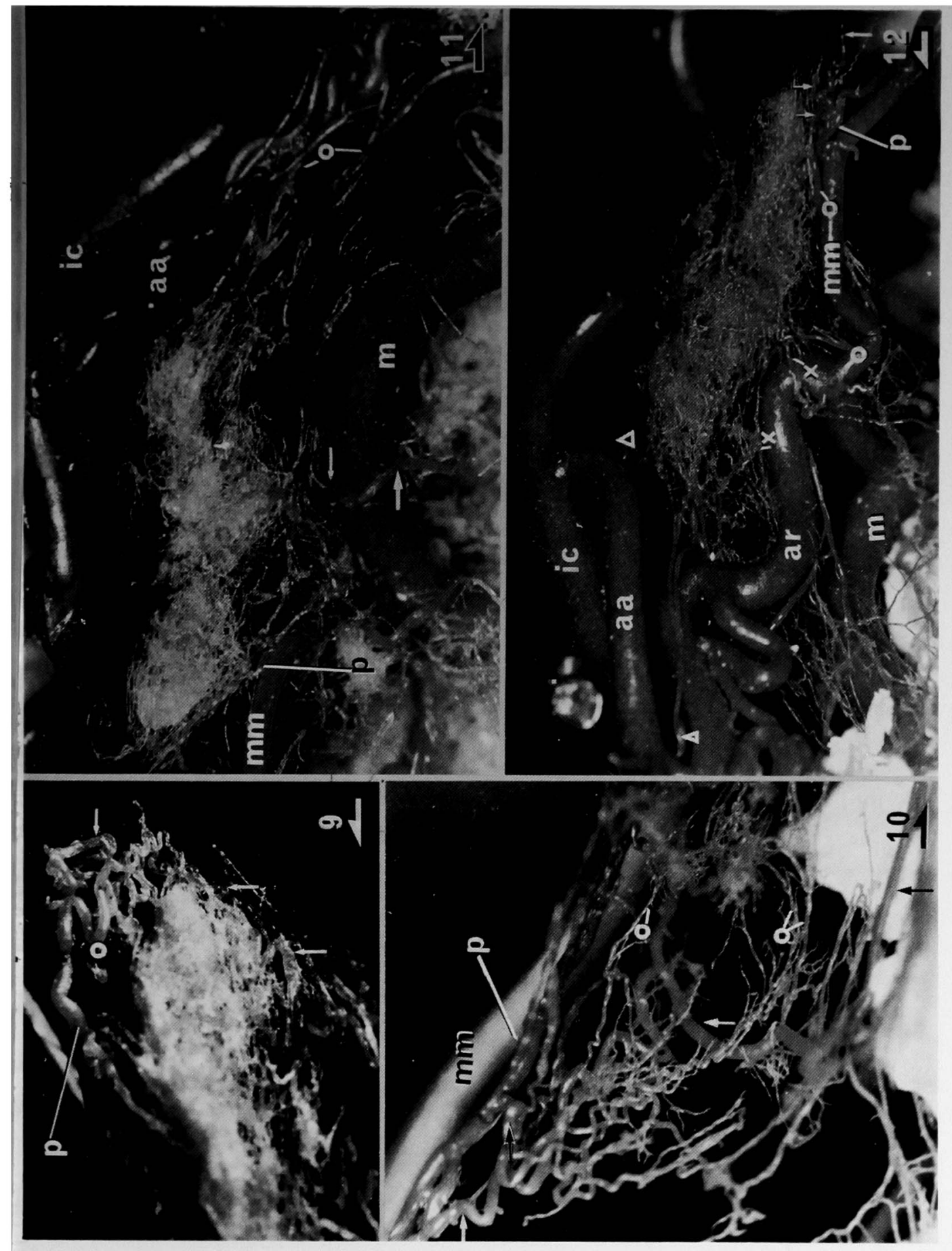

H. Okuda 


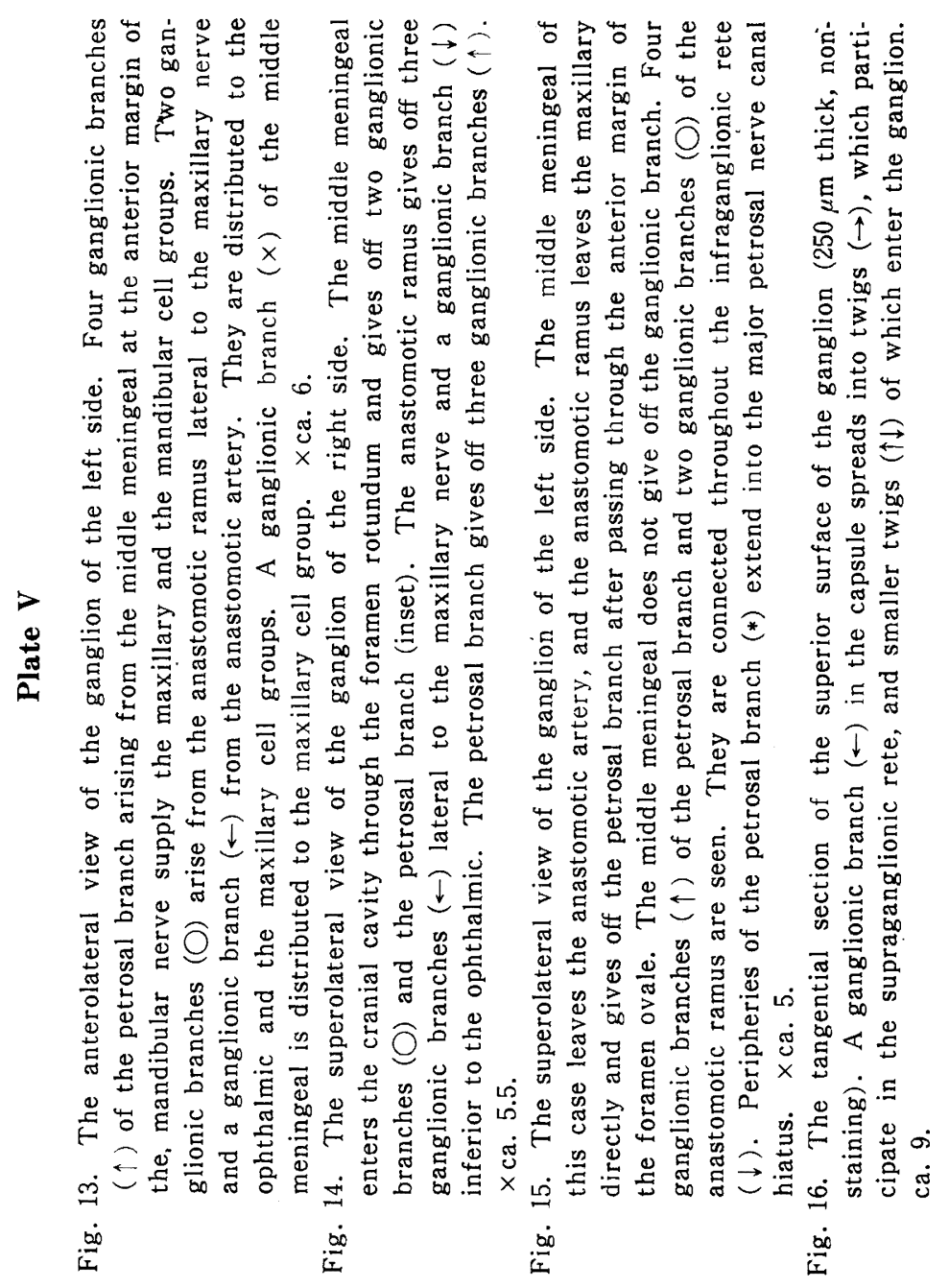


Plate V

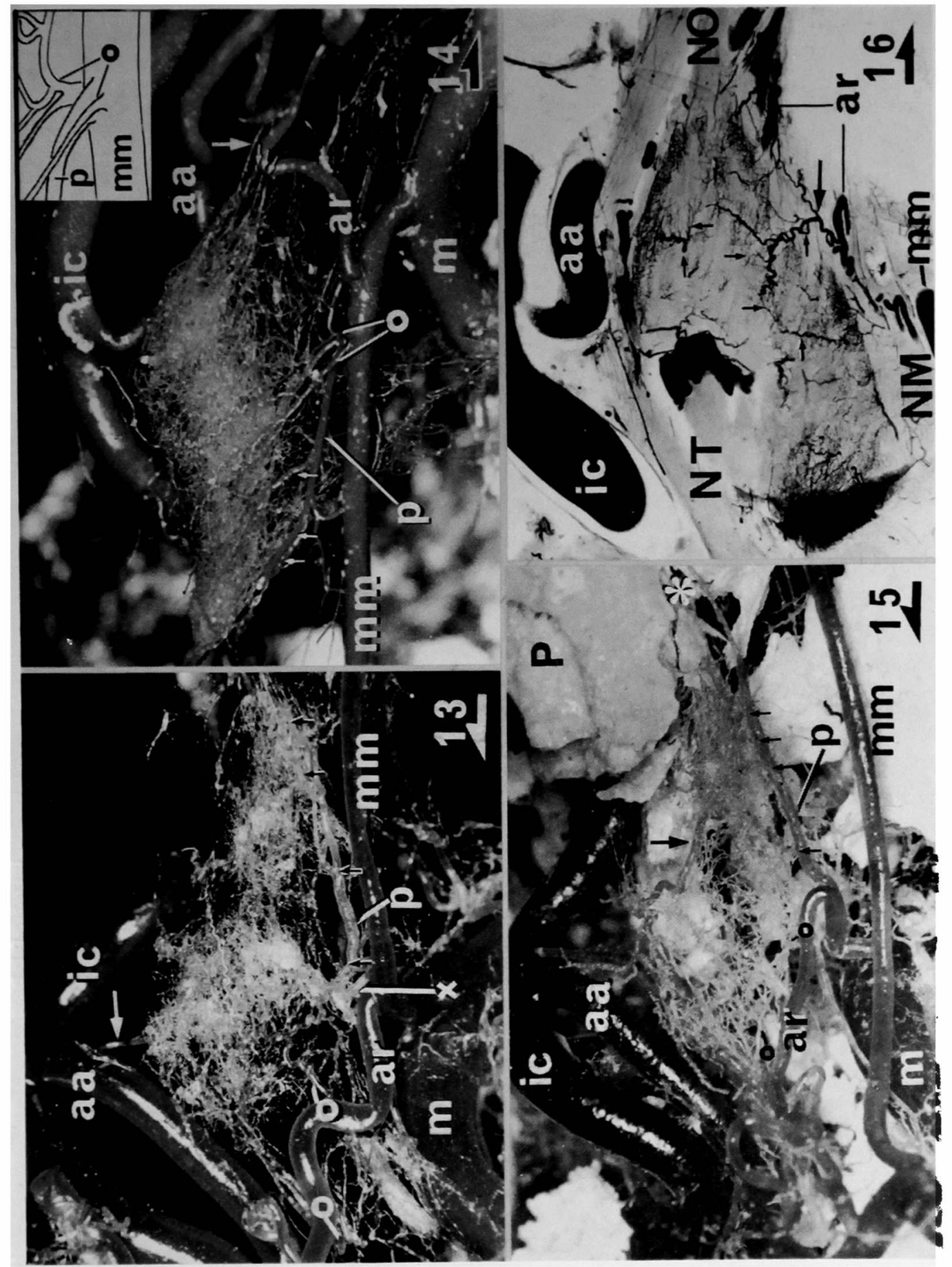




\section{Plate VI}

Fig. 17. The horizontal section in the height of the fork between the ophthalmic and the maxillary divisions ( $250 \mu \mathrm{m}$ thick, non-staining). Ganglionic branches $(\triangle)$ pass along the concavity (central side) of the ganglion and spread twigs anterolaterally $(\uparrow$ ) and posteromedially $(\downarrow)$. Other ganglionic branches $(x)$ run across the maxillary and the mandibular divisions and spread twigs $(\leftarrow)$ posteromedially, which supply these divisions. Other ganglionic branches $\left(^{*}\right)$ of the petrosal branch are seen in the tongue-like part of the mandibular division. $\times$ ca. 15 .

Fig. 18. The frontal section through the posterior margin of the foramen ovale $(30 \mu \mathrm{m}$ thick, hematoxylin-eosin staining). $\times$ ca. 62 .

Fig. 19. Scanning elcetron microscopic photograph of vascular casts of the mandibular division of the ganglion. $\times$ ca. 120 . In figures 18 and 19, arterial twigs (O) which enter the ganglion in company with the epineurium, ramify furthermore into small twigs $(\leftarrow)$ in the perineumium to form capillary networks $\left(\searrow_{\searrow}\right.$ in the nervous cell mass. One or two nervous cells $(\downarrow)$ are held in one mesh of the network. In figure 18, the supraganglionic arterial rete $(\uparrow)$ is seen in the capsule of the ganglion $(x)$ inside the dura mater $(\nabla)$. 


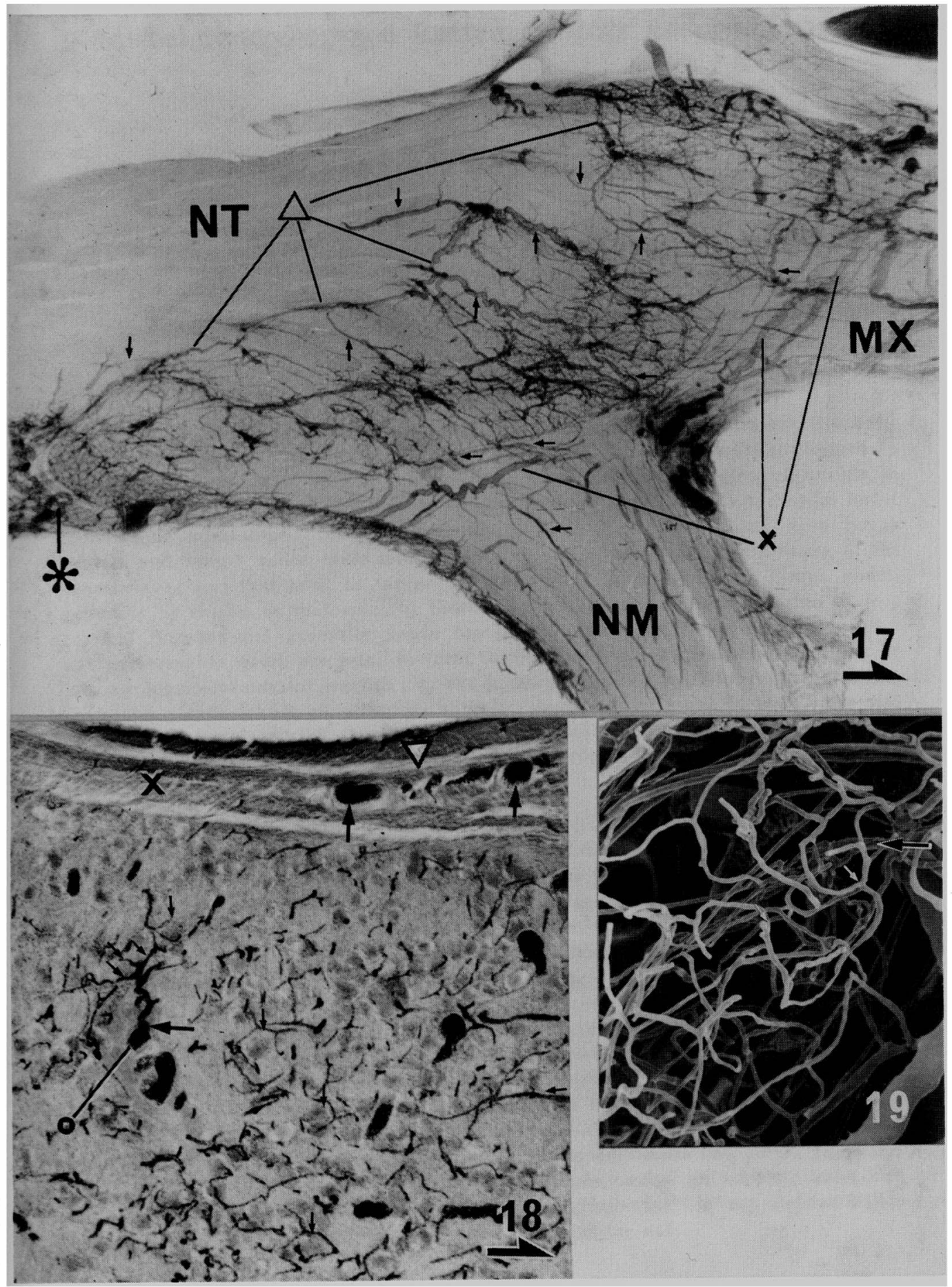

H. Okuda 